\title{
Energetic and Exergetic Investigation of Regenerative Gas Turbine Air-Bottoming/Steam -Bottoming Combined Cycle
}

\author{
Mohammad Nadeem KHAN \\ Department of Mechanical and Industrial Engineering, College of Engineering, Majmaah University, Majmaah 11952 , \\ Kingdom of Saudi Arabia, E-mail: mn.khan@mu.edu.sa \\ crossref http://dx.doi.org/10.5755/j02.mech.25099
}

\begin{abstract}
Nomenclature
$\dot{m}$ - mass flow rate, $\mathrm{kg} / \mathrm{s} ; W$ - work net output, $\mathrm{kW} ; \eta$ - thermal efficiency; $Q$ - heat supplied rate; $\mathrm{kg} / \mathrm{s} ; h$ - specific enthalpy $(\mathrm{kJ} / \mathrm{kg}) ; T I T$ - turbine inlet temperature, $\mathrm{K} ; c_{p}-$ specific heat, $\mathrm{kJ} / \mathrm{kg} . \mathrm{K} ; \varepsilon$-heat exchanger effectiveness; $r_{p}$ - pressure ratio; $x, y, z$ - mass fraction of exhaust gases; $R$ - gas constant, $\mathrm{kJ} / \mathrm{kg} . \mathrm{K} ; \gamma-$ specific heat ratio; $T$ - temperature, $\mathrm{K} ; I$ - exergy $(\mathrm{kW}) ; P$ - pressure, bar; $S F C$ - specific fuel consumption; $L C V$ - lower calorific value of fuel; H.E. - heat exchanger.

Subscripts

$T$ - turbine; $C$ - Air compressor; $c c$ - combustion chamber; $t$ - topping; $b$ - bottoming; s - steam/water; $p$ - plant; comb. - combustion chamber; $a$ - air; net - Net; exh. - exhaust; $g$ - gases; $f$ - fuel; $t h$ - thermal.
\end{abstract}

\section{Introduction}

For the country's economy and industries growth, Capacity power generation is an essential need. Along with the continuous rise of oil prices and reduction of oil supply, effective power generation systems is required to fulfil the demand of power worldwide developed [1-6]. Moreover, controlling the environmental pollution especially emission of carbon oxides by the burning of fossil fuels need special attention for cleaner power generation system [7-11]. Encouraging renewable energy technologies for accomplishing commercial growth, climate change reduction, and energy economy are considered seriously and find a suitable solution to fulfil the present as well as future energy demand. Fossil fuel prices, rising energy demand, and global warming are the major long-lasting parameters of bearable power generation. The advanced combined cycle power (CCP) plants are one of the option for to fulfil the energy demand because of its outstanding performance. The airbottoming combined (ABC) cycle and Steam-bottoming combined (RSBC) cycle can be replaced by the traditional power generation system because of their high performance and minimum exergy exhaust gasses losses. The power generation by this technique involves the turbine inlet temperature of topping cycle (TIT) and a mass fraction of exhaust gasses to optimize the overall cycle performance [12-14].

For base-load power generation, modified gas turbine cycle power plants are generally used with natural gas as a fuel from the last few decades. [15-19]. Utilizing the great amount of energy of exhaust gasses from the gas turbine for running another cycle which may be air-bottoming or steam bottoming give the concept of combined cycle power (CCP) plant which significantly impacts the power generation industry and are achieved popularity worldwide.
The CCP plant not only helps to increase the power generating capacity of the plant but also drastically reduces the pollution caused by the exhaust from the simple GT cycle power plant. [20-22]. Bazmi et al. [23] theoretically examines power sector development and emphasized the major section of optimization and modelling of power plant for the future demand as a tool for the ecological energy field. Chatzimouratidis et al. [24] consider the 9 end-node standards, to evaluate 10 different power plants concerning their economic, technological, and sustainability characteristics. The study emphasizes multi-criterion analysis is required to evaluate the power plant performance. They concluded that for future power generation, power plant must be operated by renewable energy. Ibrahim et al. [25] thermodynamically investigated energy and exergy analysis of gas turbine power plant components and overall plant. Results show that air compressor has maximum exergy and energy efficiency followed by gas turbine and combustion chamber. Study also suggest some recommendations to enhance the cycle performance. Gazikhani et al. [26] investigate conventional $\mathrm{ABC}$ cycle performance specific fuel consumption $(S F C)$, work output, and the component exergy destruction and compare the results with simple gas turbine. The results show that the fuel exergy raises by $4.7-7.4 \%$ due to components of air bottoming cycle and specific work is increased by $15.4 \%$ with the decrease of $S F C$ by $13.3 \%$.

Until now, several combined cycles have been proposed by many researchers with using different techniques to analyse its performance. Khan et al. [27] examined the theoretical 3 different types of configurations of the combined cycle and compared with a simple gas turbine cycle. By varying the turbine inlet temperature and pressure ratio of the topping cycle, this study evaluates the three suggested combined cycle energetic performance like thermal efficiency, work net output, specific fuel consumption $(S F C)$, and exergetic performance like exhaust gas exergy losses and exergy destruction. It was observed from the study that the TIT significantly affects energetic and exergetic performance of suggested cycles. Ibrahim et al. [28] reviewed various types of gas turbine power plant covering simple as well as complex gas turbine power plants. Study focus on major parameters that effects the plant performance and finally suggest some section of improvement to improve the gas turbine power plant performance and min minimize the losses.

It is observed from the above literature survey; CCP plant performance may be enhanced by several techniques. Most of the studies cover various parameters like pressure ratio, turbine inlet temperature, etc. affecting the CCP plant performance. The novelty of the present study is that it investigates the energetic and exergetic performance 
of the Air-bottoming/Steam-bottoming combined cycle by varying the mass fraction of exhaust gasses and TIT of the topping cycle. The energetic performance covers the work net output, thermal efficiency, and $S F C$ whereas the exhaust gasses exergy loss, plant exergy, and exergy efficiency falls in exergetic performance of the topping cycle, RABC cycle, and RSBC cycle. Also, energetic and exergetic performance of topping cycle, RABC cycle and RSBC cycle by varying the $T I T$ of topping cycle $(1000 \mathrm{~K} \leqslant T I T \leqslant 1500 \mathrm{~K})$ and mass fraction of exhaust gasses $(0 \leqslant x \leqslant 1)$ are presented graphically.

\section{Cycle description}

The proposed cycle description shown in Fig. 1 consist of topping cycle (GT cycle) and bottoming cycles (GT cycle or Rankine cycle). In the topping cycle, air at pressure $P_{1}$ and ambient temperature $T_{1}$ enters the air compressor, where its temperature and pressure rise to $T_{2}$ and $P_{2}$, respectively. The temperature of compressed air rises from $T_{2}$ to $T_{3}$ and temperature of exhaust gasses temperature decreases to $T_{6}$ from $T_{5}$ in first heat exchanger $\left(H . E_{1}\right)$. The compressed air at temperature $T_{3}$ and pressure $P_{2}$ goes to combustion chamber and combustion gasses enters the gas turbine at pressure $P_{2}$ and temperature $T_{4}$, where it expands to pressure $P_{1}$ and leave at temperature $T_{5}$. The partial mass of exhaust gasses $(x)$ from the gas turbine leaves the environment through first heat exchanger $\left(H . E_{1}\right)$.

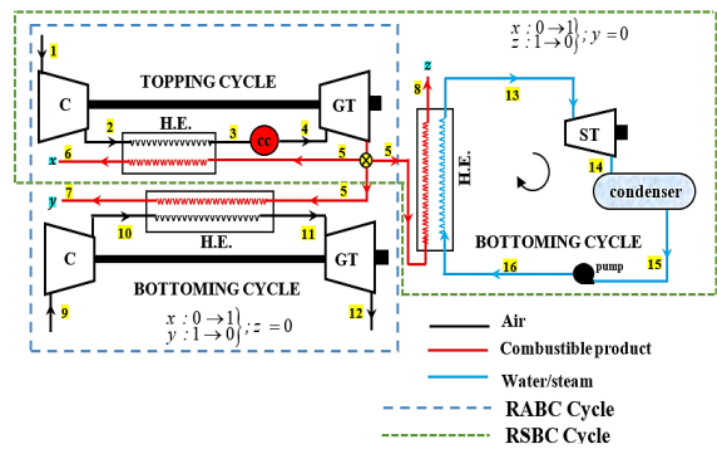

Fig. 1 Schematic of regenerative air bottoming/Steam bottoming combined cycle

In air-bottoming gas turbine cycle, air leaves the air compressor at pressure $P_{10}$ and temperature $T_{10}$ from the inlet condition of temperature $T_{9}\left(=T_{1}\right)$ and pressure $P_{9}\left(=P_{1}\right)$. The compressed air is heated by partial mass $(y=1-x)$ of the exhaust gasses from the topping gas turbine in the second heat exchanger $\left(H . E_{2}\right)$, due to which temperature of compressed air increases from $T_{10}$ to $T_{11}$ whereas the temperature of the partial mass $(y)$ of exhaust gasses decreases from $T_{5}$ to $T_{7}$. The compressed air at temperature of $T_{11}$ enters the turbine after leaving $H . E_{2}$ of the bottoming cycle, where it expands to pressure $P_{12}\left(=P_{1}\right)$ and temperature $T_{12}$. In steambottoming Rankine cycle, water having the specific enthalpy of $h_{16}$ enter the heat exchanger $\left(H . E_{3}\right)$, where it gains heat from the partial mass of exhaust gasses $(z=1-x)$ of topping cycle. Due to this heat transfer the temperature of exhaust gasses leaving through the $H . E_{3}$ decreases from $T_{5}$ to $T_{8}$ whereas the water converted to steam having the specific enthalpy of $h_{13}$. The steam at specific enthalpy of $h_{13}$ and pressure $P_{13}$ enters the steam turbine where it expands to condenser pressure of $P_{14}$.
The exhaust steam from the steam turbine enters the steam condenser where it condenses to water at saturated temperature at condenser pressure. This saturated water is again pumped back to heat exchanger $\left(H . E_{3}\right)$.

\section{Analysis of topping cycle}

\section{Energy analysis}

Work required to run the compressor:

$$
\left(W_{c}\right)_{t}=\left(\dot{m}_{a}\right)_{t}\left(h_{2}-h_{1}\right) \text {, }
$$

where: $T_{2}=T_{1}\left\{1+\left(r_{p t}^{\alpha}-1\right) / \eta_{c}\right\}$ and

$$
\alpha=\left(\gamma_{a}-1\right) / \gamma_{a}
$$

Work from gas turbine:

$$
\left(W_{T}\right)_{t}=\dot{m}_{g}\left(h_{4}-h_{5}\right),
$$

where: $T_{5}=T_{4}\left\{1-\eta_{t}\left(1-r_{p t}^{-\beta}\right)\right\}$ and

$$
\begin{aligned}
& \beta=\left(\gamma_{g}-1\right) / \gamma_{g}, \\
& \dot{m}_{g}=\left(\dot{m}_{a}\right)_{t}+\dot{m}_{f},
\end{aligned}
$$

where:

$$
\dot{m}_{f}=\left(\dot{m}_{a}\right)_{t} \cdot\left\{\left(c_{p g} \cdot T_{4}-c_{p a} \cdot T_{3}\right) /\left(L C V-c_{p g} \cdot T_{4}\right)\right\} .
$$

The topping cycle work net output is:

$\left(W_{n e t}\right)_{t}=\left(W_{G T}\right)_{t}-\left(W_{c}\right)_{t}$.

The topping cycle thermal efficiency is:

$\left(\eta_{t h}\right)_{t}=\left(W_{n e t}\right)_{t} / Q$.

The topping cycle $S F C$ is:

$(S F C)_{t}=\left(3.6 \times 10^{5}\right) /\left(\left(\eta_{t h}\right)_{t} \cdot L C V\right)$.

For first heat exchanger (H. E. $)_{1}$ in Eq. (10) below:

$$
\begin{aligned}
& \left(\dot{m}_{a}\right)_{t} \cdot\left(h_{3}-h_{2}\right)=x \cdot \dot{m}_{g} \cdot\left(h_{5}-h_{6}\right)= \\
& =\varepsilon_{1} \cdot\left[x \cdot \dot{m}_{g} \cdot h_{5}-\left(\dot{m}_{a}\right)_{t} \cdot h_{2}\right] .
\end{aligned}
$$

Therefore:

$$
\begin{aligned}
& T_{3}=\left(1-\varepsilon_{1}\right) T_{2}+x \cdot\left(\dot{m}_{g} /\left(\dot{m}_{a}\right)_{t}\right) \cdot\left(c_{p g} / c_{p a}\right) \cdot \varepsilon_{1} \cdot T_{5}, \\
& T_{6}=T_{5}-(1 / x) \cdot\left(\left(\dot{m}_{a}\right)_{t} / \dot{m}_{g}\right) \cdot\left(c_{p a} / c_{p g}\right) \cdot\left(T_{3}-T_{2}\right) .
\end{aligned}
$$

\section{Energy analysis}

Exhaust gasses exergy loss is:

$\left(I_{e x h}\right)_{t}=x \cdot \dot{m}_{g} \cdot c_{p g}\left[\left(T_{6}-T_{1}\right)-T_{1} \cdot \ln \left(T_{6} / T_{1}\right)\right]$. 
The topping cycle air compressor exergy loss is:

$$
\left(I_{C}\right)_{t}=\left(\dot{m}_{a}\right)_{t} \cdot T_{1} \cdot\left[c_{p a} \cdot \ln \left(T_{2} / T_{1}\right)-R_{a} \cdot \ln \left(r_{p t}\right)\right] .
$$

The topping cycle exergy loss in $H . E_{l}$ is:

$$
\begin{aligned}
& \left(I_{H \cdot E_{1} 1}\right)_{t}=\left(\dot{m}_{a}\right)_{t} \cdot c_{p a}\left[\left(T_{3}-T_{2}\right)-T_{1} \cdot \ln \left(T_{3} / T_{2}\right)\right]+ \\
& +\dot{m}_{g} \cdot c_{p g}\left[\left(T_{5}-T_{6}\right)-T_{1} \cdot \ln \left(T_{5} / T_{6}\right)\right] .
\end{aligned}
$$

is:

The topping cycle exergy loss in the gas turbine

$$
\left(I_{G T}\right)_{t}=\dot{m}_{g} \cdot T_{1} \cdot\left[c_{p g} \cdot \ln \left(T_{5} / T_{4}\right)-R_{g} \cdot \ln \left(1 / r_{p t}\right)\right] .
$$

The combustion chamber supply heat is given by:

$(\dot{Q})=\dot{m}_{g} \cdot c_{p g} \cdot T_{4}-\left(\dot{m}_{a}\right)_{t} \cdot c_{p a} \cdot T_{3}$.

Plant Exergy distraction:

$\left(I_{p}\right)_{t}=\left(I_{C}\right)_{t}+\left(I_{c c}\right)_{t}+\left(I_{H \cdot E_{1}}\right)_{t}+\left(I_{G T}\right)_{t}$.

The topping cycle exergy efficiency is:

$\left(\eta_{\text {exergy }}\right)_{t}=\left(I_{p}\right)_{t} / Q$.

\section{Analysis of RABC cycle}

\section{Energy analysis}

Compressor work is given by:

$$
\left(W_{c}\right)_{b}=\left(\dot{m}_{a}\right)_{b}\left(h_{10}-h_{9}\right) \text {, }
$$

where:

$$
T_{10}=T_{9}\left\{1+\left(r_{p b}^{\alpha}-1\right) / \eta_{c}\right\} .
$$

The turbine Work is given by:

$$
\left(W_{G T}\right)_{b}=\left(\dot{m}_{a}\right)_{b} \cdot\left(h_{11}-h_{12}\right),
$$

where:

$$
T_{11}=T_{10}\left\{1-\eta_{t}\left(1-r_{p b}^{-\alpha}\right)\right\} .
$$
given by:

The work net output of the bottoming cycle is

$$
\left(W_{n e t}\right)_{g b}=\left(W_{G T}\right)_{b}-\left(W_{c}\right)_{b} .
$$

The RABC cycle work net output is:

$$
\left(W_{\text {net }}\right)_{R A B C}=\left(W_{n e t}\right)_{t}+\left(W_{n e t}\right)_{g b} \text {. }
$$

The RABC cycle thermal efficiency is:

$$
\left(\eta_{t h}\right)_{R A B C}=\left(W_{n e t}\right)_{R A B C} / Q \text {. }
$$

The RABC cycle $S F C$ is:

$$
(S F C)_{R A B C}=\left(3.6 \times 10^{5}\right) /\left(\left(\eta_{t h}\right)_{R A B C} . L C V\right) .
$$

For second heat exchanger (H. E.l):

$$
\begin{aligned}
& \left(\dot{m}_{a}\right)_{b} \cdot c_{p a} \cdot\left(T_{11}-T_{10}\right)=y \cdot \dot{m}_{g} \cdot c_{p g} \cdot\left(T_{5}-T_{7}\right)= \\
& =\varepsilon_{2} \cdot\left[y \cdot \dot{m}_{g} \cdot c_{p g} \cdot T_{5}-\left(\dot{m}_{a}\right)_{b} \cdot c_{p a} \cdot T_{10}\right] .
\end{aligned}
$$

Therefore:

$$
\begin{aligned}
& T_{11}=\left\{1-\varepsilon_{2}\right\} \cdot T_{10}+y \cdot \varepsilon_{2} \cdot\left(\dot{m}_{g} /\left(\dot{m}_{a}\right)_{b}\right) \cdot\left(c_{p g} / c_{p a}\right) \cdot T_{5}, \\
& T_{7}=T_{5}-(1 / y) \cdot\left(\left(\dot{m}_{a}\right)_{b} / \dot{m}_{g}\right) \cdot\left(c_{p a} / c_{p g}\right) \cdot\left(T_{11}-T_{10}\right) .
\end{aligned}
$$

\section{Energy analysis}

The exhaust gasses exergy loss is:

$$
\left(I_{e x h}\right)_{b}=y \cdot\left(\dot{m}_{g}\right) \cdot c_{p g}\left[\left(T_{7}-T_{1}\right)-T_{1} \cdot \ln \left(T_{7} / T_{1}\right)\right] .
$$

The air compressor exergy loss is given as:

$$
\left(I_{C}\right)_{b}=\left(\dot{m}_{a}\right)_{b} \cdot T_{1} \cdot\left[c_{p a} \cdot \ln \left(T_{10} / T_{9}\right)-R_{a} \cdot \ln \left(r_{p b}\right)\right] \text {. }
$$

The $H . E_{2}$ of the bottoming cycle exergy is given by:

$$
\begin{aligned}
& \left(I_{H . E .2}\right)_{b}=\left(\dot{m}_{a}\right)_{b} \cdot c_{p a}\left[\left(T_{11}-T_{10}\right)-T_{1} \cdot \ln \left(T_{11} / T_{10}\right)\right]+ \\
& +y \cdot \dot{m}_{g} \cdot c_{p g}\left[\left(T_{5}-T_{7}\right)-T_{1} \cdot \ln \left(T_{5} / T_{7}\right)\right] .
\end{aligned}
$$

The gas turbine exergy loss is given by:

$$
\left(I_{G T}\right)_{b}=\left(\dot{m}_{a}\right)_{b} \cdot T_{1} \cdot\left[c_{p g} \cdot \ln \left(T_{12} / T_{11}\right)-R \cdot \ln \left(1 / r_{p b}\right)\right] .
$$
given by:

Plant Exergy distraction of bottoming cycle is

$$
\left(I_{p}\right)_{b}=\left(I_{C}\right)_{b}+\left(I_{H . E .2}\right)_{b}+\left(I_{G T}\right)_{b} .
$$
given by:

The Plant Exergy distraction of RABC cycle is

$$
\left(I_{p}\right)_{R A B C}=\left(I_{p}\right)_{t}+\left(I_{p}\right)_{b} .
$$

The exergy efficiency RABC cycle is given by:

$$
\left(\eta_{\text {exergy }}\right)_{R A B C}=\left(I_{p}\right)_{R A B C} / Q \text {. }
$$

\section{Analysis of RSBC cycle}

\section{Energy analysis}

The work from the turbine:

$$
\left(W_{S T}\right)_{b}=\left(\dot{m}_{s}\right)_{b} \cdot\left(h_{13}-h_{14}\right) \text {. }
$$

The pump work of steam bottoming cycle: 


$$
\left(W_{\text {pump }}\right)_{b}=\left(\dot{m}_{s}\right)_{b} \cdot\left(h_{16}-h_{15}\right) .
$$

The work net output of the steam bottoming cycle is:

$$
\left(W_{\text {net }}\right)_{s b}=\left(W_{S T}\right)_{b}-\left(W_{\text {pump }}\right)_{b} .
$$

The RSBC cycle work net output is given by:

$$
\left(W_{n e t}\right)_{R S B C}=\left(W_{n e t}\right)_{t}+\left(W_{n e t}\right)_{s b} .
$$

The RSBC cycle thermal efficiency is given by:

$$
\left(\eta_{t h}\right)_{R S B C}=\left(W_{n e t}\right)_{R S B C} / Q \text {. }
$$

The RSBC cycle $S F C$ is given by:

$$
(S F C)_{R S B C}=\left(3.6 \times 10^{5}\right) /\left(\left(\eta_{t h}\right)_{R S B C} . L C V\right) .
$$

\section{Energy analysis} cycle is:

The exhaust gasses exergy loss steam bottoming

$$
\left(I_{e x h}\right)_{b}=z \cdot\left(\dot{m}_{g}\right) \cdot c_{p g}\left[\left(T_{7}-T_{1}\right)-T_{1} \cdot \ln \left(T_{7} / T_{1}\right)\right] .
$$
cycle is:

The steam turbine exergy loss of steam bottoming

$$
\left(I_{S T}\right)_{b}=\left(\dot{m}_{s}\right)_{b} \cdot T_{1} \cdot\left[s_{14}-s_{13}\right] .
$$

The $H . E_{3}$ exergy loss of steam bottoming cycle is:

$$
\begin{aligned}
& \left(I_{H . E .3}\right)_{b}=z \cdot \dot{m}_{g} \cdot c_{p g}\left[\left(T_{5}-T_{8}\right)-T_{1} \cdot \ln \left(T_{5} / T_{8}\right)\right]+ \\
& +\left(\dot{m}_{s}\right)_{b}\left[\left(h_{16}-h_{13}\right)-T_{1} \cdot\left(s_{16}-s_{13}\right)\right] .
\end{aligned}
$$
given by:

The steam bottoming cycle Exergy distraction is

$$
\left(I_{p}\right)_{s b}=\left(I_{S T}\right)_{b}+\left(I_{H . E .3}\right)_{b}+\left(I_{\text {pump }}\right)_{b}+\left(I_{\text {cond }}\right)_{b} .
$$

The RSBC cycle exergy distraction is given by:

$$
\left(I_{p}\right)_{R S B C}=\left(I_{p}\right)_{t}+\left(I_{p}\right)_{s b} .
$$

The RSBC cycle exergy efficiency of topping cycle is given by:

$$
\left(\eta_{\text {exergy }}\right)_{R S B C}=\left(I_{p}\right)_{R S B C} / Q .
$$

\section{Solution technique}

The mass fraction of the exhaust gasses $(x, y, z)$ and turbine inlet temperature (TIT) of topping cycle as the input variables for the analyses of net-work output, thermal efficiency, $S F C$, exhaust gasses exergy loss, plant exergy destruction, and exergy efficiency of RABC cycle and RSBC cycle using Engineering Equation Solver (EES) software. The assumed parameters are listed in Table 1.
Table 1

List of assumed parameters and variables

\begin{tabular}{|lc|}
\hline Turbine inlet temperature TIT & 1000 to $1500 \mathrm{~K}$ \\
Pressure ratio of topping cycle $r_{p t}$ & 5 \\
Pressure ratio of topping cycle $r_{p b}$ & 2 \\
Compressor isentropic efficiency & $80 \%$ \\
Turbine isentropic efficiency & $85 \%$ \\
Isentropic efficiency of steam turbine & $85 \%$ \\
Compressor inlet \& ambient temperature & $300 \mathrm{~K}$ \\
Effectiveness of exchangers & 0.9 \\
Air flow rate of topping and RABC & $1 \mathrm{~kg} / \mathrm{s}$ \\
Lower calorific value of fuel, $\mathrm{kJ} / \mathrm{kg} . \mathrm{K}$ & 42000 \\
\hline
\end{tabular}

\section{Results and discussion}

The Turbine inlet temperature (TIT) as well as the mass fraction of gas turbine exhaust gasses is used to analyze the energetic and exergetic performance of regenerative gas turbine air bottom/steam bottoming combined cycle in the present study. The exhaust gasses of the topping cycle pass through the heat exchangers of the bottoming cycles through the controlled valve, which regulates the gas turbine exhaust gasses to the heat exchangers. The effect of inlet temperature (TIT) and the mass fraction of the exhaust gasses $(x, y, z)$ on the work net output, thermal efficiency, $S F C$, plant exergy destruction, and exergy efficiency of the combined cycle are investigated parametrically using first and second law of thermodynamic.

The variation of work net output of topping, RABC cycle and RSBC cycle with respect to fraction of exhaust gasses and TIT of topping cycle is shown in Fig. 2. The work net output of topping cycle is almost unaffected by the fraction of exhaust gasses $(x)$ but greatly affected by TIT. As TIT increases from $1000 \mathrm{~K}$ to $1500 \mathrm{~K}$, the work net output of topping cycle increased by $161.5 \%$ at $x=0$ and $159.6 \%$ at $x=0$. In Fig. 2 for RABC cycle $z=0$, and for RSBC cycle $y=0$ means the exhaust gasses of topping cycle exchanges its heat in first-second and first-third heat exchanger respectively. At $x=0$ and $z=0$, the complete amount of exhaust gasses passes through the second heat exchanger and exchanges its heat with the air bottoming cycle whereas at $x=0$ and $y=0$, the complete amount of exhaust gasses passes through the third heat exchanger and exchanges its heat with the steam bottoming cycle.

For RABC cycle, work net output attained its peak value at $x=0$ because the complete amount of exhaust gasses passes through the second heat exchanger and exchanges its heat with air bottoming cycle. This means that the work output of air bottoming cycle is maximum at $x=0$ and decreases as " $x$ " increases and reaches to almost zero at $x=0.5$ for $T I T=1000 \mathrm{~K}$ and $x=0.75$ for $T I T=1500 \mathrm{~K}$. At $x=0$, the work output of air-bottoming cycle is $22.1 \%$ and $27.3 \%$ of topping cycle for $T I T=1000 \mathrm{~K}$ and $T I T=1500 \mathrm{~K}$ respectively. This means that work output of RABC cycle increased by $24.7 \%$ and $31 \%$ with respect to regenerative gas turbine cycle at $x=0$ for $T I T=1000 \mathrm{~K}$ and $T I T=1500 \mathrm{~K}$ respectively. For RSBC cycle, work output of steam bottoming cycle is maximum at $x=0$ and decreases as " $x$ " increases and reaches to almost zero at $x=1.0$ for $T I T=1000 \mathrm{~K}$ and $T I T=1500 \mathrm{~K}$. The work output of RSBC cycle increased by $50.3 \%$ and $34.7 \%$ with respect to regenerative gas turbine cycle at $x=0$ for $T I T=1000 \mathrm{~K}$ and $T I T=1500 \mathrm{~K}$ respectively. Moreover, at $x=0.5$ for $T I T=1000 \mathrm{~K}$ and $x=0.75$ for $T I T=1500 \mathrm{~K}$, the work output of RABC cycle is same as topping cycle 
whereas the work output of RSBC cycle is still $23.8 \%$ and $7.8 \%$ more than that of topping cycle at $x=0.5$ for $T I T=1000$ $\mathrm{K}$ and $x=0.75$ for $T I T=1500 \mathrm{~K}$ respectively. The variation of thermal efficiency of topping, RABC cycle and RSBC cycle with respect to fraction of exhaust gasses $(x)$ and TIT of topping cycle is shown in Fig. 3. The thermal efficiency of topping cycle, RABC cycle and RSBC cycle is significantly affected by the fraction of exhaust gasses $(x)$ and TIT.

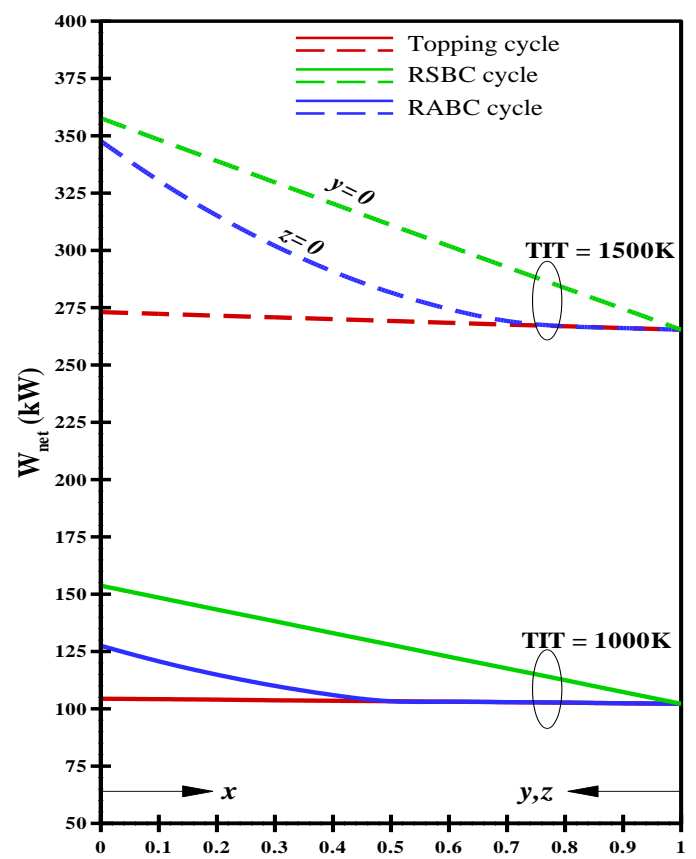

Fig. 2 Work net output of topping, RABC cycle and RSBC Cycle with respect to $(x)$ at $T I T=1000 \mathrm{~K}$ and $1500 \mathrm{~K}$

For RABC cycle, the thermal efficiency attained its peak value at $x=1.0$ because the complete amount of exhaust gasses passes through the first heat exchanger and exchanges its heat with topping cycle. The thermal efficiency of both RABC cycle and RSBC cycle increases as " $x$ " increases. At $x=0.5$ for $T I T=1000 \mathrm{~K}$ and $x=0.75$ for $T I T=1500$ $\mathrm{K}$ the thermal efficiency of RABC cycle is same as topping cycle because at this condition the work output of RABC cycle is same as work output of topping cycle. At $x=0$, the thermal efficiency of RABC cycle increased by $22.1 \%$ and $27.3 \%$ with respect to simple gas turbine cycle for $T I T=1000 \mathrm{~K}$ and $T I T=1500 \mathrm{~K}$ respectively. For RSBC cycle, the thermal efficiency increased by $47.2 \%$ and $31 \%$ with respect to simple gas turbine cycle for $T I T=1000 \mathrm{~K}$ and $T I T=1500 \mathrm{~K}$ respectively at $x=0$. Fig. 4 shows the variation of Specific fuel consumption ( $S F C$ ) of topping, RABC cycle and $\mathrm{RSBC}$ cycle with respect to fraction of exhaust gasses and $T I T$ of topping cycle. It is clear from the graph that $S F C$ of topping cycle, RABC cycle and RSBC cycle decrease with increase of the fraction of exhaust gasses $(x)$ as well as TIT of topping cycle. The SFC of topping cycle is maximum for topping cycle as compared to RABC cycle and RSBC cycle because the work output of RABC cycle and RSBC cycle is more than that of topping cycle. When the work output and thermal efficiency of RABC cycle and RSBC cycle is equal to topping cycle at this stage the $S F C$ of RABC cycle and RSBC cycle is also equal to $S F C$ of topping cycle.

The amount of energy carried by the combustible product from the combustion chamber is use to produce power in the gas turbine. Even if the isentropic efficiency of

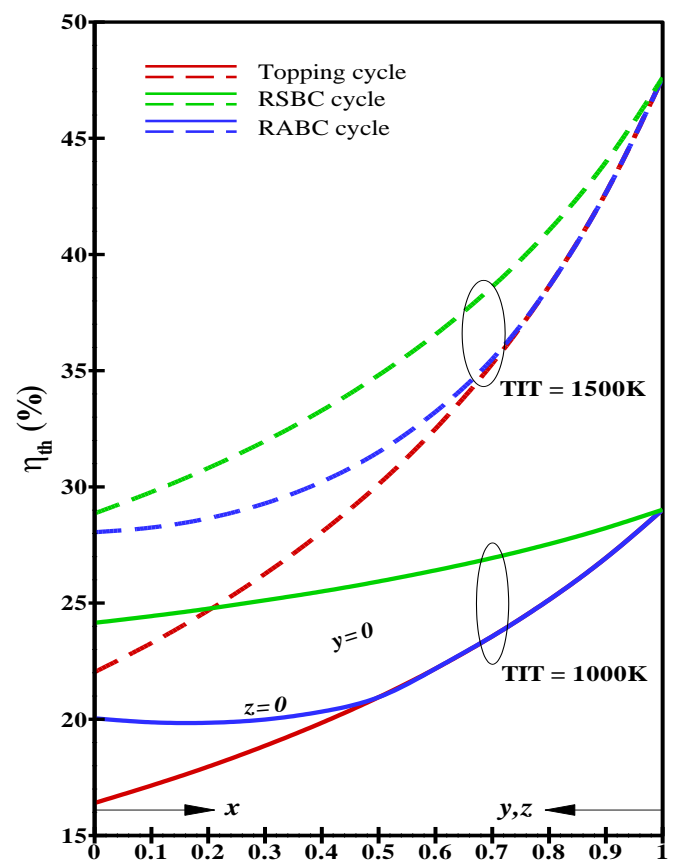

Fig. 3 Thermal efficiency of topping, RABC cycle and RSBC Cycle with respect to $(x)$ at $T I T=1000 \mathrm{~K}$ and $1500 \mathrm{~K}$

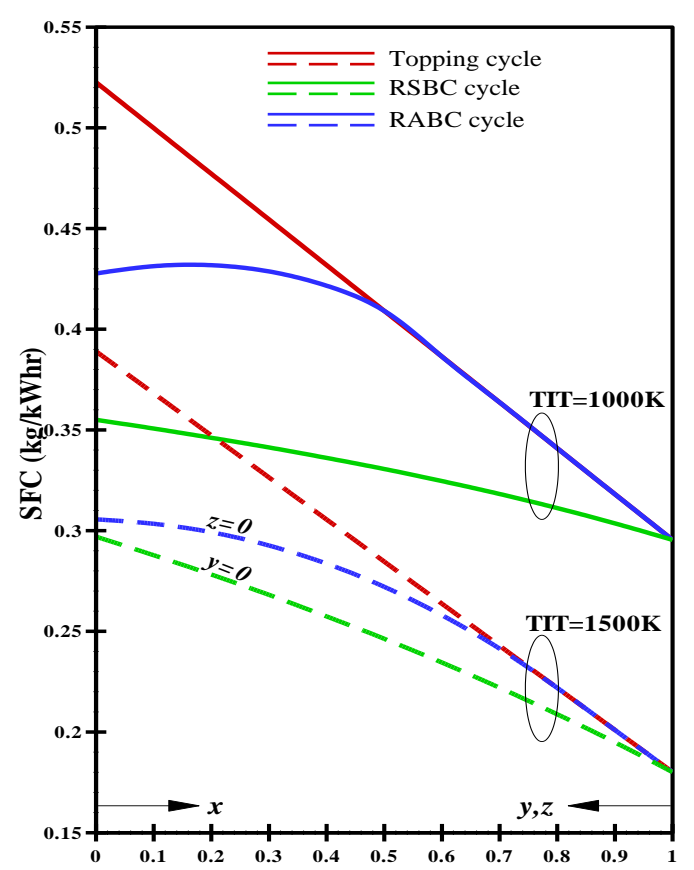

Fig. 4 SFC of topping, RABC cycle and RSBC Cycle with respect to $(x)$ at $T I T=1000 \mathrm{~K}$ and $1500 \mathrm{~K}$

$100 \%$ the complete amount of this energy is not used to produce power which results in rejection of energy through the exhaust gasses.

The energy loss through the exhaust gasses causes global warming and help to enhance many toxics air pollution. Researchers always try to find out the solution to minimize the energy loss through the exhaust gasses. Fig. 5 shows the exergy loss by the exhaust gasses with respect to fraction of exhaust gasses and TIT of topping cycle for topping, RABC cycle and RSBC cycle.

It is observed that the variation of exhaust gasses exergy loss with respect to fraction of exhaust gasses $(x)$ is 


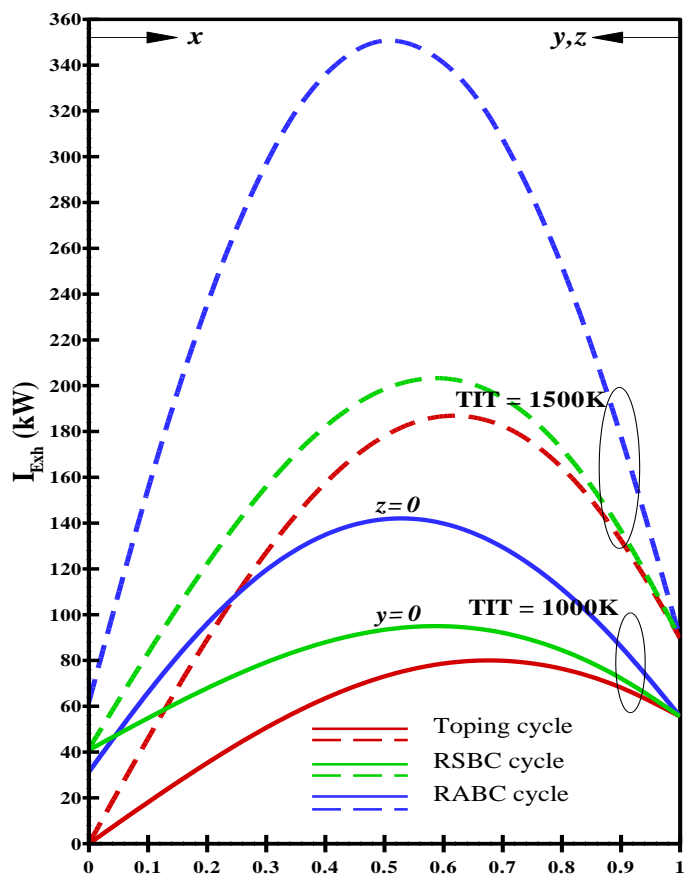

Fig. 5 Exhaust gasses exergy loss of topping, RABC cycle and RSBC Cycle with respect to $(x)$ at $T I T=1000 \mathrm{~K}$ and $1500 \mathrm{~K}$

seem to parabolic. For both $T I T=1000 \mathrm{~K}$ and $T I T=1500 \mathrm{~K}$, the exhaust gasses exergy loss in case of topping, RABC cycle and RSBC cycle is minimum at $x=0$. For $T I T=1000 \mathrm{~K}$, the exhaust gasses exergy loss reaches its maximum value at $x=0.7, x=0.5$, and $x=0.6$ in case of topping cycle, RABC cycle and RSBC cycle respectively whereas for $T I T=1500 \mathrm{~K}$, the exhaust gasses exergy loss reaches its maximum value at $x=0.6, x=0.5$, and $x=0.6$ in case of topping cycle, RABC cycle and RSBC cycle respectively. At $x=1$, the exhaust gasses exergy loss for $T I T=1500 \mathrm{~K}$ is $61.6 \%$ more than that of exhaust gasses exergy loss for $T I T=1000 \mathrm{~K}$. The peak value of exhaust gasses exergy loss from $\mathrm{RABC}$ cycle is $49.2 \%$ for $T I T=1000 \mathrm{~K}$ and $72.5 \%$ for $T I T=1500 \mathrm{~K}$ more than that of RSBC cycle. The Plant or total exergy destruction of the cycle is the summation of exergy destruction of each component of the cycle. As the number of components increases plant exergy destruction is proportionally increases. Fig. 6 shows the plant exergy destruction with respect to mass fraction of exhaust gasses $(x)$ and TIT of topping cycle. It is clear from the figure that plant exergy destruction increases with TIT.

The plant exergy destruction of RABC cycle is more than RSBC cycle and topping cycle for both $T I T=1000 \mathrm{~K}$ and $T I T=1500 \mathrm{~K}$ and the reason is that the total number of components in RABC cycle is more as compared to RSBC cycle and topping cycle.

Exergy efficiency is the ratio of plant exergy destruction to total heat supplied by combustion of fuel where the rate of fuel supply depends on inlet and outlet temperature of combustible product, lower calorific value of fuel and air flow rate in topping cycle. The variation of exergy efficiency of the cycle with respect to mass fraction of exhaust gasses $(x)$ and TIT of topping cycle.

It is observed from Fig. 7 that energy efficiency increases with TIT and the exergy efficiency of topping cycle is least value as compared to RSBC cycle followed by RABC cycle. At $x=0$, the exergy efficiency of topping cy-

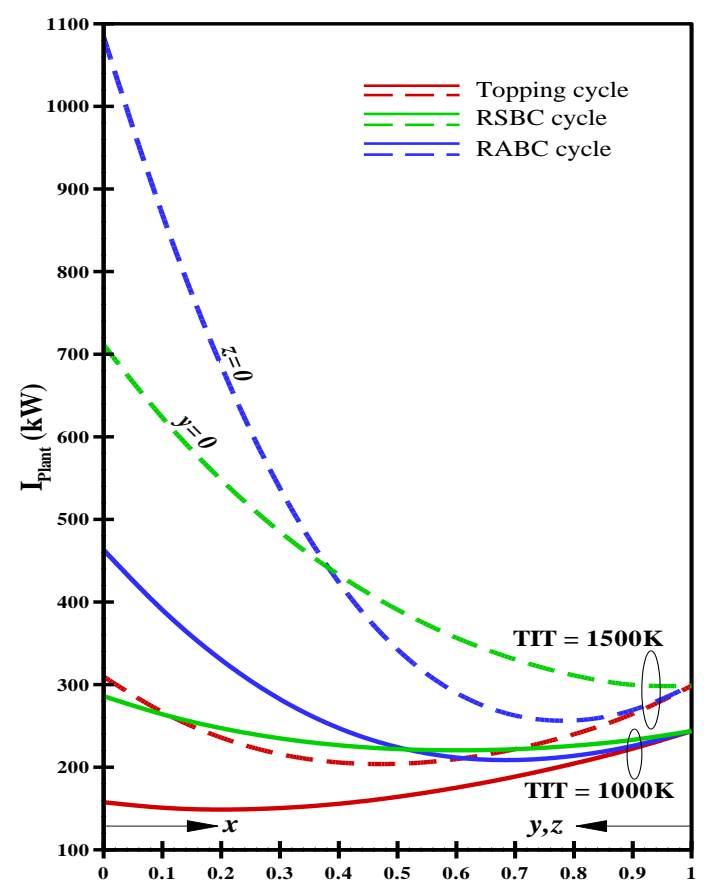

Fig. 6 Plant exergy destruction of the plant with respect to (x) at $T I T=1000 \mathrm{~K}$ and $1500 \mathrm{~K}$

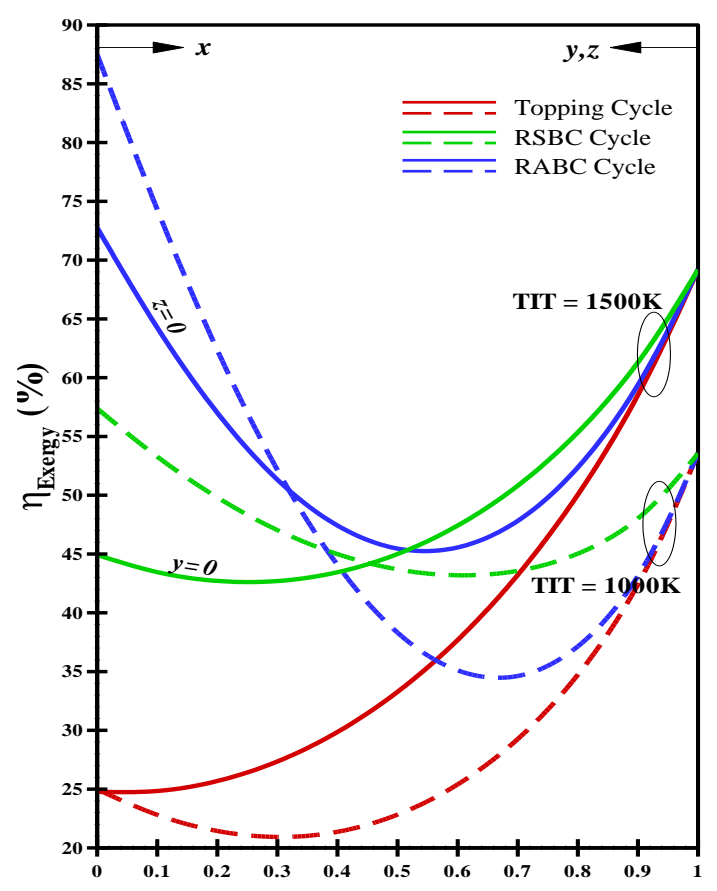

Fig. 7 Exergy efficiency of topping, RABC cycle and RSBC Cycle with respect to $(x)$ at $T I T=1000 \mathrm{~K}$ and $1500 \mathrm{~K}$

cle, RABC cycle and RSBC cycle at $T I T=1500 \mathrm{~K}$ is $0.85 \%$, $20.2 \%$, and $27.7 \%$ more than that of exergy efficiency at $T I T=1000 \mathrm{~K}$. Moreover, at $x=0$ and $T I T=1000 \mathrm{~K}$, the exergy efficiency of RABC cycle is $61.9 \%$ more than that of RSBC cycle and the exergy efficiency of RSBC cycle is $69.2 \%$ more than that of topping cycle whereas at $x=0$ and $T I T=1500 \mathrm{~K}$, the exergy efficiency of RABC cycle is $52.5 \%$ more than that of RSBC cycle and the exergy efficiency of RSBC cycle is $129.7 \%$ more than that of topping cycle. For $T I T=1000 \mathrm{~K}$, the least value of exergy efficiency of topping cycle, RABC cycle, and RSBC cycle is observed at $x=0$ but for $T I T=1500 \mathrm{~K}$, the least value of exergy efficiency of topping cycle, RABC cycle, and RSBC cycle is observed at $x=0.3, x=0.7$, and $x=0.6$ respectively. 


\section{Conclusion}

The energetic and exergetic has been analysed parametrically for the regenerative gas turbine air-bottoming/steam bottoming combined cycle. The mass fraction of exhaust gasses $(x)$ and TIT of topping cycle are use as the independent variables to analyse the performance of topping cycle, RABC cycle and RSBC cycle. The present study focus on the analyses of energy related parameters like work net output, thermal efficiency, and specific fuel consumption and exergy related parameters like exhaust gasses exergy loss, plant exergy and exergy efficiency. Based on above analyses following are the major conclusions of this study:

1. The work net output, thermal efficiency and SFC of topping cycle, RABC cycle and RSBC cycle is significantly affected by turbine inlet temperature (TIT).

2. For work net output RSBC cycle is the best option followed by RABC cycle and topping cycle. And for thermal efficiency regenerative gas turbine cycle is the best option and have no comparison with RABC cycle and RSBC cycle. For $S F C$, regenerative gas turbine cycle is the best option as compared to RABC cycle and RSBC cycle.

3. The exhaust gasses exergy losses of RABC cycle is minimum followed by RSBC cycle at $x=0$ for $T I T=1000 \mathrm{~K}$ but for $T I T=1000 \mathrm{~K}$ at $x=0$, the exhaust gasses exergy losses by the RSBC cycle is minimum followed by RABC cycle.

4. The total exergy destruction of regenerative gas turbine cycle is minimum and have no compression with RABC cycle and RSBC cycle for both $T I T=1000 \mathrm{~K}$ and $T I T=1500 \mathrm{~K}$.

5. The exergy efficiency of regenerative gas turbine cycle is least as compared to RABC cycle and RSBC cycle for both $T I T=1000 \mathrm{~K}$ and $T I T=1500 \mathrm{~K}$ but exergy efficiency at $T I T=1000 \mathrm{~K}$ is less as compared to exergy efficiency at $T I T=1500 \mathrm{~K}$.

Overall, this paper shows that for optimal work net output RSBC cycle is preferable as compared to RABC cycle and regenerative gas turbine cycle but for thermal efficiency, and $S F C$, regenerative gas turbine cycle is preferred. The RSBC cycle is the best option for minimizing the exhaust gasses exergy losses.

\section{Acknowledgements}

The author acknowledges the Deanship of Scientific Research (DSR) at Majmaah University, Majmaah Saudi Arabia, for technical and financial support through Vote Number 1439-47 for this research project.

\section{References}

1. Gao, M.; Beig, G.; Song, S.; Zhang, H.; Hu, J.; Ying, Q.; Liang, F.; Liu, Y.; Wang, H.; Lu, X.; Zhu, T.; Carmichael, G. R.; Nielsen, C. P.; McElroy, M. B. 2018. The impact of power generation emissions on aAmbient PM 2.5 pollution and human health in China and India, Environment International 121:250-259. https://doi.org/10.1016/j.envint.2018.09.015.

2. Gadalla, M.; Saghafifar, M. 2017. Energy and exergy analyses of pulse combustor integration in air bottoming cycle power plants, Applied Thermal Engineering
121:674-687.

https://doi.org/10.1016/j.applthermaleng.2017.04.070.

3. Dagilis, V. 2013. Combined heat pump and power plant. Part I: Thermodynamic Analysis, Mechanika 19(1):1924.

https://doi.org/10.5755/j01.mech.19.1.3630.

4. Yazawa, K.; Shakouri, A. 2016. Thermoelectric topping cycles with scalable design and temperature dependent material properties, Scripta Material 111:58-63. https://doi.org/10.1016/j.scriptamat.2015.05.037.

5. Liang, Y.; Cai, L.; Guan, Y.;Liu, W.; Han, Y.; Xiang, Y. 2019. Performance Simulation on an integrated natural gas-, N2- and organic fluid-cycle thermal power plant, Energy Procedia 158:1871-1878. https://doi.org/10.1016/j.egypro.2019.01.434.

6. Saghafifar, M.; Gadalla, M. 2017. Thermo-economic optimization of hybrid solar maisotsenko bottoming cycles using heliostat field collector: comparative analysis, Applied Energy 190:686-702.

https://doi.org/10.1016/j.apenergy.2016.12.165.

7. Mossi Idrissa, A. K.; Goni Boulama K. 2017. Investigation of the Performance of a combined brayton/brayton cycle with humidification, Energy 141: 492-505.

https://doi.org/10.1016/j.energy.2017.09.097.

8. Gogoi, T. K.; Gautam, U. 2019. Performance evaluation of a gas and steam turbine based cogeneration plant: a case study, ASME conference, paper number: GTINDIA2019-2358.

https://doi.org/10.1115/GTINDIA2019-2358.

9. Pantaleo, A. M.; Camporeale, S. M.; Sorrentino, A.; Miliozzi, A.; Shah, N.; Markides, C. N. 2017. Solar/biomass hybrid cycles with thermal storage and bottoming orc: system integration and economic analysis, Energy Procedia 129:724-731.

https://doi.org/10.1016/j.egypro.2017.09.105.

10. Saghafifar, M.; Gadalla, M. 2017. Thermo-economic evaluation of water-injected air bottoming cycles hybridization using heliostat field collector: comparative analyses, Energy 119:1230-1246.

https://doi.org/10.1016/j.energy.2016.11.067.

11. Tariq, R.; Sheikh, N. A. 2018. Numerical heat transfer analysis of maisotsenko humid air bottoming cycle - a study towards the optimization of the air-water mixture at bottoming turbine inlet, Applied Thermal Engineering 133: 49-60. https://doi.org/10.1016/j.applthermaleng.2018.01.024.

12. Li, Y.; Zhang, G.; Bai, Z.; Song, X.; Wang, L.; Yang, Y. 2018. Backpressure adjustable gas turbine combined cycle: a method to improve part-load efficiency, Energy Conversion Management 174:739-754. https://doi.org/10.1016/j.enconman.2018.07.077.

13.Saghafifar, M.; Omar, A.; Erfanmoghaddam, S.;Gadalla, M. 2017. Thermo-Economic analysis of recuperated maisotsenko bottoming cycle using triplex air saturator: comparative analyses, Applied Thermal Engineering 111: 431-444. https://doi.org/10.1016/j.applthermaleng.2016.09.100.

14. Farres-Antunez, P., Xue, H., White, A. J. 2018 Thermodynamic Analysis and Optimisation of a Combined Liquid Air and Pumped Thermal Energy Storage Cycle, Journal Energy Storage 18:90-102. https://doi.org/10.1016/j.est.2018.04.016.

15. Cameretti, M.; Langella, G.; Sabino, S.; Tuccillo, R. 
2015. Modeling of a hybrid solar microgas turbine power plant, Energy Procedia 82: 833-840. https://doi.org/10.2306/scienceasia15131874.2006.32.187.

16. Neumann, N.; Peitsch, D. 2019. Potentials for pressure gain combustion in advanced gas turbine cycles, Applied Science 9(16):3211-3232. https://doi.org/10.3390/app9163211.

17. Ibrahim, T. K.; Mohammed, M. K.; Awad, O. I.; Abdalla, A. N.; Basrawi, F.; Mohammed, M. N.; Najafi, G.; Mamat, R. 2018 A comprehensive review on the exergy analysis of combined cycle power plants, Renewable and Sustainable Energy Reviews 90: 835-850. https://doi.org/10.1016/j.rser.2018.03.072.

18. Maheshwari, M.; Singh, O. 2017. Exergy analysis of intercooled reheat combined cycle with ammonia water mixture based bottoming cycle, Applied Thermal Engineering 121: 820-827.

https://doi.org/10.1016/j.applthermaleng.2017.04.145.

19. Kosowski, K.; Tucki, K.; Piwowarski, M.; Stẹpień, R.; Orynycz, O.; Włodarski, W. 2019 Thermodynamic cycle concepts for high-efficiency power plants. Part B: Prosumer and Distributed Power Industry, Sustainability 11(9): 2647-2660. https://doi.org/10.3390/su11092647.

20. Khorshidi, Z.; Florin, N. H.; Ho, M. T.; Wiley, D. E. 2016. Techno-economic evaluation of co-firing biomass gas with natural gas in existing NGCC plants with and without $\mathrm{CO} 2$ capture, International Journal of Green house Gas Control 49: 343-363.

https://doi.org/10.1016/j.ijggc.2016.03.007.

21. Mohammadi, K.; Saghafifar, M.; McGowan, J. G. 2018. Thermo-economic evaluation of modifications to a gas power plant with an air bottoming combined cycle, Energy Conversion. and Management 172: 619-644. https://doi.org/10.1016/j.enconman.2018.07.038.

22. Amani, M.; Smaili, A.; Ghenaiet, A. 2020. Thermoeconomic assesment of the first integrated solar combined cycle system of Hassi R'mel, Mechanika 26(3): 242-251. https://doi.org/10.5755/j01.mech.23.2.18110.

23. Bazmi, A. A.; Zahedi, G.; Hashim, H. 2015. Design of decentralized biopower generation and distribution system for developing countries, Journal of Cleaner Production 86: 209-220. https://doi.org/10.1016/j.jclepro.2014.08.084.

24. Chatzimouratidis A. I.; Pilavachi P. A. 2012. Decision support systems for power plants impact on the living standard, Energy Conversion and Management 64:182198.

https://doi.org/10.1016/j.enconman.2012.05.006.

25. Ibrahim, T. K., Basrawi, F., Awad, O. I., Abdullah, A. N., Najafi, G., Mamat, R., Hagos, F. Y. 2017. Thermal performance of gas turbine power plant based on exergy analysis, Applied Thermal Engineering 115: 977-985. https://doi.org/10.1016/j.applthermaleng.2017.01.032.

26. Ghazikhani, M.;Khazaee, I.; Abdekhodaie, E. 2014 Exergy analysis of gas turbine with air bottoming cycle,
Energy 72:599-607.

https://doi.org/10.1016/j.energy.2014.05.085.

27. Khan, M. N.; Tlili, I.; Khan, W. A. 2017. Thermodynamic optimization of new combined gas/ steam power cycles with HRSG and heat exchanger, Arabian Journal for Science and Engineering 42(11): 4547-4558. https://doi.org/10.1007/s13369-017-2549-4.

28. Ibrahim, T. K.; Mohammed, M. K.; Al Doori, W. H. A.; Al-Sammarraie, A. T.; Basrawi, F. 2019. Study of the performance of the gas turbine power plants from the simple to complex cycle: a technical review, Journal of Advance Research in Fluid Mechanics abd Thermal Science 57(2): 228-250. http://www.akademiabaru.com/arfmtsv57_n2_p228_25 0 .

\section{N. Khan}

\section{ENERGETIC AND EXERGETIC INVESTIGATION OF REGENERATIVE GAS TURBINE AIR BOTTOMING/STEAM BOTTOMING COMBINED CYCLE}

$\mathrm{S} \mathrm{u} \mathrm{m} \mathrm{m} \mathrm{a} \mathrm{r} \mathrm{y}$

The present study is a thermodynamic analysis of a Regenerative Air-Bottoming combined (RABC) cycle /Steam bottoming combined (RABC) cycle operated by the exhaust gases the topping gas turbine cycle. The fractional mass of exhaust gases passes through the first heat exchanger where it exchanges heat with the compressed air from the air compressor of topping cycle and remaining amount of exhaust gasses passes through a second heat exchanger where it uses to supply heat to RABC cycle or third heat exchanger where it uses to supply heat to RSBC cycle. The energetic and exergetic performance of $\mathrm{RABC}$ cycle and RSBC cycle is investigated using turbine inlet temperature $(1000 \mathrm{~K} \leqslant T I T \leqslant 1500 \mathrm{~K})$ and mass fraction of exhaust gas $(0 \leqslant x \leqslant 1)$ of the topping cycle as the input variables. The work net output attained its peak value at $x=0$ which is $22.1 \%$ to $27.3 \%$ for RABC cycle and $22.7 \%$ to $21.5 \%$ for RSBC cycle whereas the maximum thermal efficiency and minimum specific fuel consumption is observed at $x=1$. Also exergy loss by exhaust gases is minimum at $x=0$ for both RABC cycle and RSBC cycle. Finally, it is concluded that for the maximum work net output and minimum exergy loss by exhaust gases, RABC cycle is the best option followed by RSBC cycle but for optimum thermal efficiency and minimum specific fuel consumption purely regenerative gas turbine cycle have no comparison with RABC cycle and RSBC cycle.

Keywords: RABC cycle, RSBC cycle, topping cycle, heat exchanger, thermal efficiency, work net output, exergy, energy.

Received February 24, 2020 Accepted June 02, 2021 